\title{
COAL PLASTICITY AT HIGH HEATING RATES AND TEMPERATURES
}

\author{
Fifth Technical Progress Report \\ Sarakorn Gerjarusak, William A. Peters, and Jack B. Howard \\ Energy Laboratory and Department of Chemical Engineering \\ MASSACHUSETTS DNSTITUTE OF TECHNOLOGY \\ Cambridge, Massachusetts 02139

\section{DISCLADMER}

This report was prepared as an account of work sponsored by an agency of the United States Government. Neither the United States

Government, nor any agency thereof, nor any of their employees, makes any warranty, express or implied, or assumes any legal liability or responsibility for the accuracy, completeness or usefulness of any information, apparatus, product, or process disclosed, or represents that its use would not infringe privately owned rights. Reference herein to any specific commercial product, process, or service by trade name, trademark, manufacturer, or otherwise, does not necessarily constitute or imply its endorsement, recommendation, or favoring by the United States Government or any agency thereof. The views and opinions of authors expressed herein do not necessarily state or reflect those of the United States Government or any agency thereof.

Submitted to the United States Department of Energy Pittsburgh Energy Technology Center Attention: Dr. Philip M. Goldberg

PREPARED FOR THE UNITED STATES DEPARTMENT OF ENERGY Under Contract No. DE-FG22-89PC-89773

Date Submitted: August 1991

"US/DOE Patent Clearance is not required prior to the publication of this document." 


\begin{abstract}
This report presents the Ph.D. Thesis Proposal of Mr. Sarakorn Gerjarusak to the MIT Department of Chemical Engineering on the topic: "Plasticity Kinetics of Different Coal Types." A theoretical approach to the study of coal plasticity is described. Previous work relating the viscosity of molten coal to the inventory of metaplast employed a single chemical reaction model. In order to be able to use the kinetics parameters such as the activation energy obtained at one temperature-time history io predict the plasticity of molten coal at other temperature-time histories, a multiple independent parallel reaction model will be used to interpret our plastometer data. In addition, key plastic properties of different coals such as maximum fluidity and duration of plasticity iwill be correlated to a coal-type specific parameter formulated by $\mathrm{Ko}$, and requiring only the elemental composition of the parent coal. Finally, the plastic properties of each coal will be correlated to the tar yield from that coal to test a model which assumes metaplast to be the precursor of $\operatorname{tar}$.
\end{abstract}




\section{Proposal Contents}

1. Introduction 2

2. Literature Review 3

3. Proposed Research Plan and Methodology 8

3.1 Objectives 8

3.2 Experimental Plan 9

3.3 Theoretical Approach 18

$\begin{array}{ll}\text { 4. Safety } & 29\end{array}$

5. Timetable 31

6. References 32 


\section{Introduction}

Upon heating, bituminous coals soften and create a fluid-like mass often referred as metaplast. The coal remains soften for a period of time and then resolidifies to form coke. The softened coal is a combination of solid materials (mineral matters and organic constituents that do not soften) and metaplast. The softened coal may also contain bubbles of gaseous products from pyrolysis. The thermoplastic behavior of coal is directly related to its pyrolysis kinetics. At elevated temperature $(>650 \mathrm{~K})$, the parent coal starts to physically melt and devolatize (Loison et. al., 1963 and Fong, 1986). The resulting products include metaplast and gaseous species which can undergo further secondary reactions to produce tar, char, and other gaseous species.

A good understanding of coal's transient plastic behavior is therefore needed to supplement studies of coal pyrolysis kinetics. Parameters such as heating rate and holding temperatures are expected to significantly affect coal in modern coal conversion processes such as in reactivity and agglomeration in the coal gasification in fixed or fluidized bed reactors and combustion of fluidized or suspension-fixed coal particles. In addition, conditions in which the coal's fluidity is high are desirable for high reactivity in coal liquefaction (Whitehurst, 1980). A better understanding of coal devolatization and plasticity will also be beneficial for studies of pollutant generation in coal combustion, e.g. survival of unburned char and mineral matter size distribution. 


\section{Literature Review}

Bituminous coals heated to $650 \mathrm{~K}$ or greater exhibit transient plastic behavior. The coal particles soften, swell, and resolidify to form coke (Loison et. al., 1963). When coal melts and devolatizes, its fluidity increases to a maximum for a period of time and then deceases. Fitzgerald (1956) modeled the thermoplastic behavior of coal by the metaplast theory:

$$
\begin{aligned}
\text { coal }-->\text { metaplast }-->\text { primary gas } & \\
& + \text { semicoke }--->\text { secondary gas } \\
& + \text { coke }
\end{aligned}
$$

The fluidity of the coal melt is dependent on the amount of the liquid metaplast existing throughout the coal at any time during devolatization. Fong et. al. (1985c) found that the amount of pyridine extractables of pyrolyzed coal could be correlated with the fluidity of the coal at various temperature-time histories. Darivakis (1989) also reported that the amount of pyridine extractables and tar yields depended on the selected temperature-time history of the coal during pyrolysis.

Previous observations of the coal's thermoplastic behavior have been made under coking conditions. The heating rates used were low $(<0.1 \mathrm{~K} / \mathrm{s})$, and the maximum temperatures were generally below 
$800 \mathrm{~K}$ (ASTM, 1974). A commonly used instrument is the Gieseler plastometer. Powdered coal is compacted into a small cylindrical chamber containing a stirrer with blades or arms. The axis of the stirrer is subjected to a constant torque. The coal is heated rapidly to the temperature of about $573 \mathrm{~K}$, and then the heating rate is kept constant at about $3 \mathrm{~K} / \mathrm{min}$. The angular velocity of the stirrer is recorded as a function of time or temperature. The plastic period of coal is observed between 650-750 $\mathrm{K}$ (Loison et. al., 1963).

The Gieseler plastometer's data provide only a qualitative understanding of coal's thermoplastic behavior. The viscosity of the coal melt cannot be readily obtained directly from the measured angular velocity. The Gieseler plastometer can be calibrated using a standard of known viscosity, and the measured angular velocity can be translated into an apparent viscosity. However, this apparent viscosity has little physical significance since the angular velocity of the stirrer depends not only the true viscosity of the coal sample, but also on the complex flow field created in the cylindrical chamber. Other investigators such Davis and Echterhoff have created a number variable-torque plastometers. By keeping the angular velocity of the stirrer constant, the thermoplastic behavior of coal is observed by recording the transient torque data. Again, the heating rates and maximum temperatures of such plastometers are low, and the quantitative interpretation of the transient torque data is difficult due to the nature of the stirrer (Loison et. al., 1963). Other plastometers include the Braben plastograph, the Sapozhinokov plastometer, the concentric cylinder viscometer (Stephens, 1963), the 
capillary viscometer (Davies et. al., 1983), and the microdilatometer of Khan and Jenkins (1984).

In general it is difficult to interpret the data from the previously described plastometers quantitatively in term of the coal viscosity. Fong (1986) studied the transient plastic behavior of coal using a rapid-heating, fast-response plastometer he developed. The configuration of Fong's plastometer is a parallel disk viscometer in which the angular velocity of the shearing disk is constant (Figure 1.). The viscosity of the pyrolyzing coal sample is calculated from the recorded torque required to rotate the disk at constant speed. Fong et. al. (1985b) related the formation/depletion kinetics of pyridine extractables (assumed to approximate the metaplast) to the observed transient plastic behavior of rapidly pyrolyzed coal (Figure 2.). The transient viscosity of the coal melt was related to the concentration of metaplast by an equation adapted from an equation of Frankel and Acrivos (1967) for the viscosity of solid in liquid suspensions:

$$
\mu_{\mathrm{rel}}=9 / 8 \cdot \phi^{1 / 3} /\left(1-\phi^{1 / 3}\right)
$$

where $\mu_{\text {rel }}$ is the ratio of the actual viscosity and solid-free viscosity of the coal melt, $\phi$ is $1-M$, and $M$ is the concentration of metaplast.

However, Fong et. al. studied the thermoplastic behavior of only one particular coal (Pittsburgh bituminous No. 8). In addition, they performed experiments at only one shear rate $\left(1.98 \mathrm{~s}^{-1}\right)$. Coal 


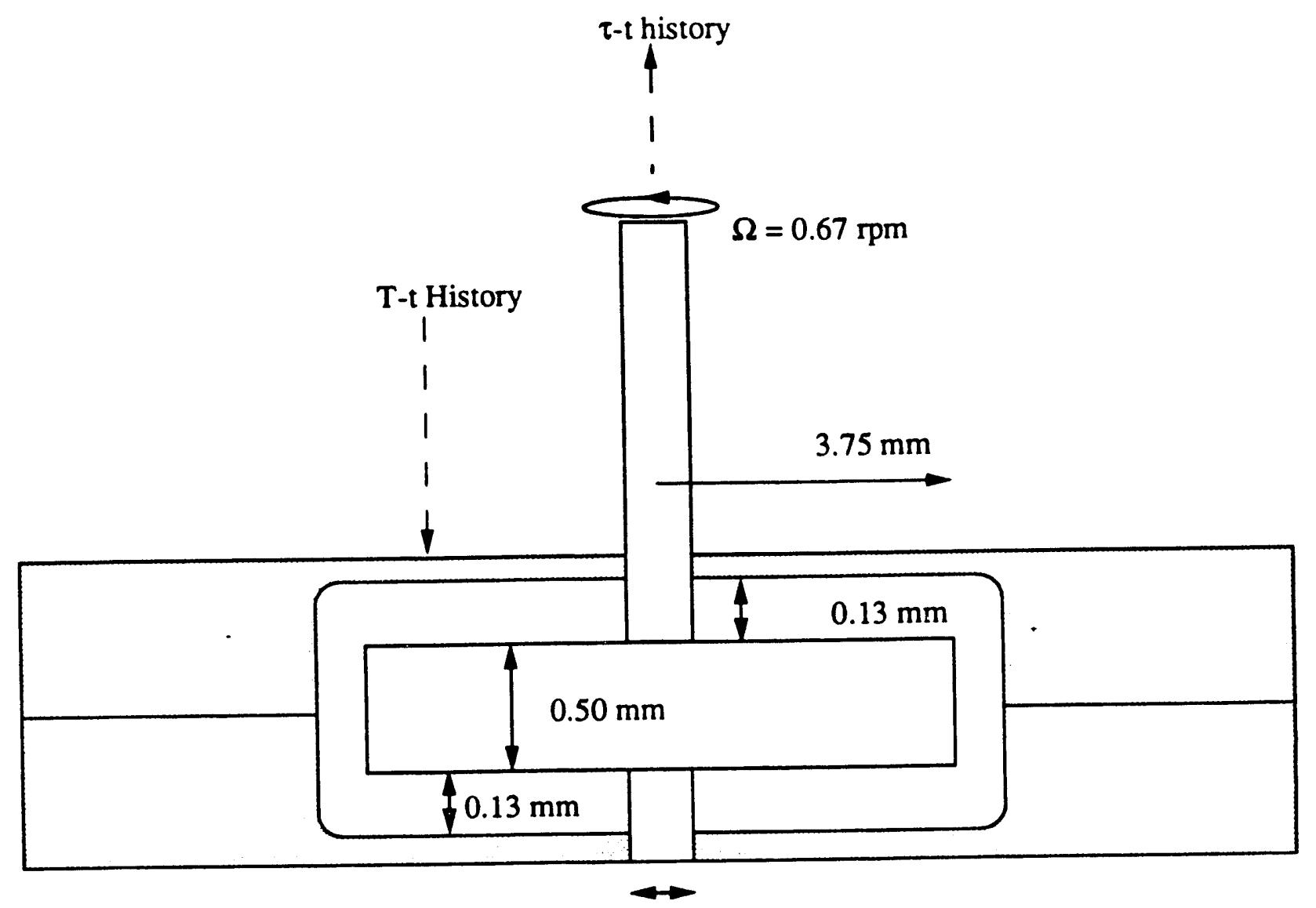

Figure 1: Fong's flat-disk plastometer configuration 


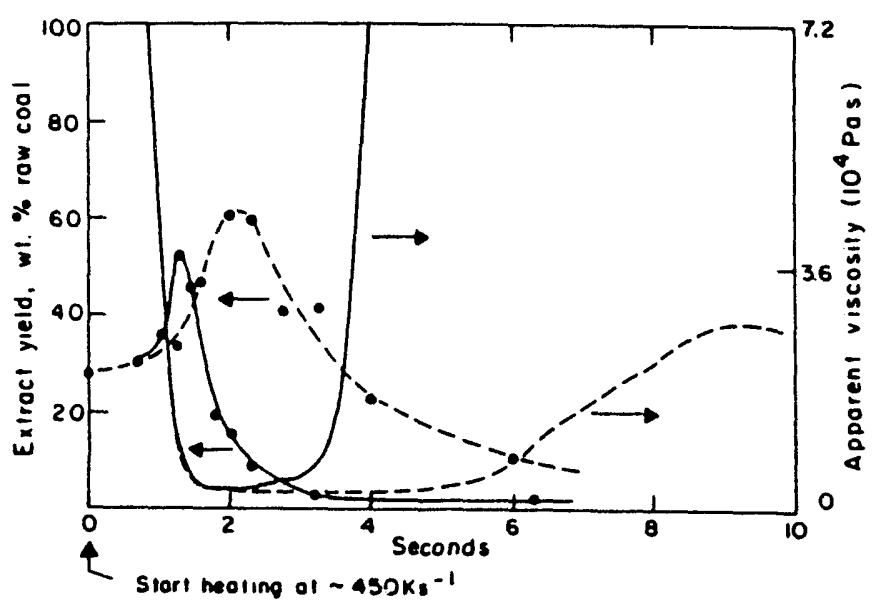

FIGURE 2: COMPARISON OF PLASTIC BEHAVIOR AND PYRIDINEEXTRACTABLES FORMATION AND DISTRUCTION. HOLDING TEMPERATURE: —— , $910 \mathrm{~K} ;-\cdots-.--.-, 855 \mathrm{~K}$. (FONG et al., 1935c) 
plasticity data are needed for other coal types and shear rates and for temperature-time histories and pressures other than those studied by Fong. In general, the factors governing the plastic properties of coal include heating rate, particle size, coal type, pressure, shear rate, and pretreatment of the coal sample (Loison et. al., 1963 and Howard, 1981).

\section{Proposed Research Plan anv Methodology}

\subsection{Objectives}

The goal of this research is to provide new, quantitative understanding of the high heating rate plastic behavior of different bituminous coals, in particular data and a global model relating transient plasticity to transient intra-coal metaplast inventories. The specific objectives are:

\section{Experimental}

To measure the apparent viscosity of different bituminous coals for different gaseous atmospheres (helium or hydrogen), shear rates (1$10 \mathrm{~s}^{-1}$ ) (heating rates $(100-1000 \mathrm{~K} / \mathrm{s})$, maximum temperatures (600$1300 \mathrm{~K})$, total reaction times (1-10 s), pressures (1-100 atm), with or without pretreatment of coal. Also, to measure the metaplast concentration and tar yield during the different stages of coal pyrolysis at selected heating rates and maximum temperatures, with or without pretreatment of coal. 


\section{Theoretical}

To relate the transient viscosity of molten coal to the kinetics of metaplast generation and depletion, using the existing models and to attempt to develop improved models to take into account the heating rate, pressure, and shear rate. To attempt to relate plasticity behavior to coal types and their tar yields.

\subsection{Experimental Plan}

The apparent viscosity of coal is being measured by a modified version of the plastometer originally developed and built by Fong (1986). The modified plastometer (Figure 3.) uses the same heating circuits (up to $1000 \mathrm{~K} / \mathrm{s}$ and $1300 \mathrm{~K}$ maximum temperature) and torque transducer (up to $5 \mathrm{oz} \cdot \mathrm{in}$ or $70 \bullet 10^{-3} \mathrm{~N} \cdot \mathrm{m}$ ) as that of Fong. However, a more powerful motor $(24 \mathrm{~V}, 200 \mathrm{oz} \cdot \mathrm{in}$ maximum torque) is used to provide shear rates of up to $10 \mathrm{~s}^{-1}$.

The torque transducer measures the torque supplied by the gear motor, to rotate at constant angular velocity and thus shear rate, a shearing disk embedded in a thin layer of coal. The torque transducer is a noncontact strain gauge torquemeter. The stated response time is less than $10 \mathrm{~ms}$, and the stated maximum error is less than $0.1 \%$. The shearing disk configuration has been modified from flat to cone-shaped (Figure 4.). This will allow the viscosity of the coal melt to be calculated without the assumption that the melt is Newtonian. The apparent viscosity, $\eta$, is obtained by applying the equation for a concentric cone-and-plate viscometer in which the 


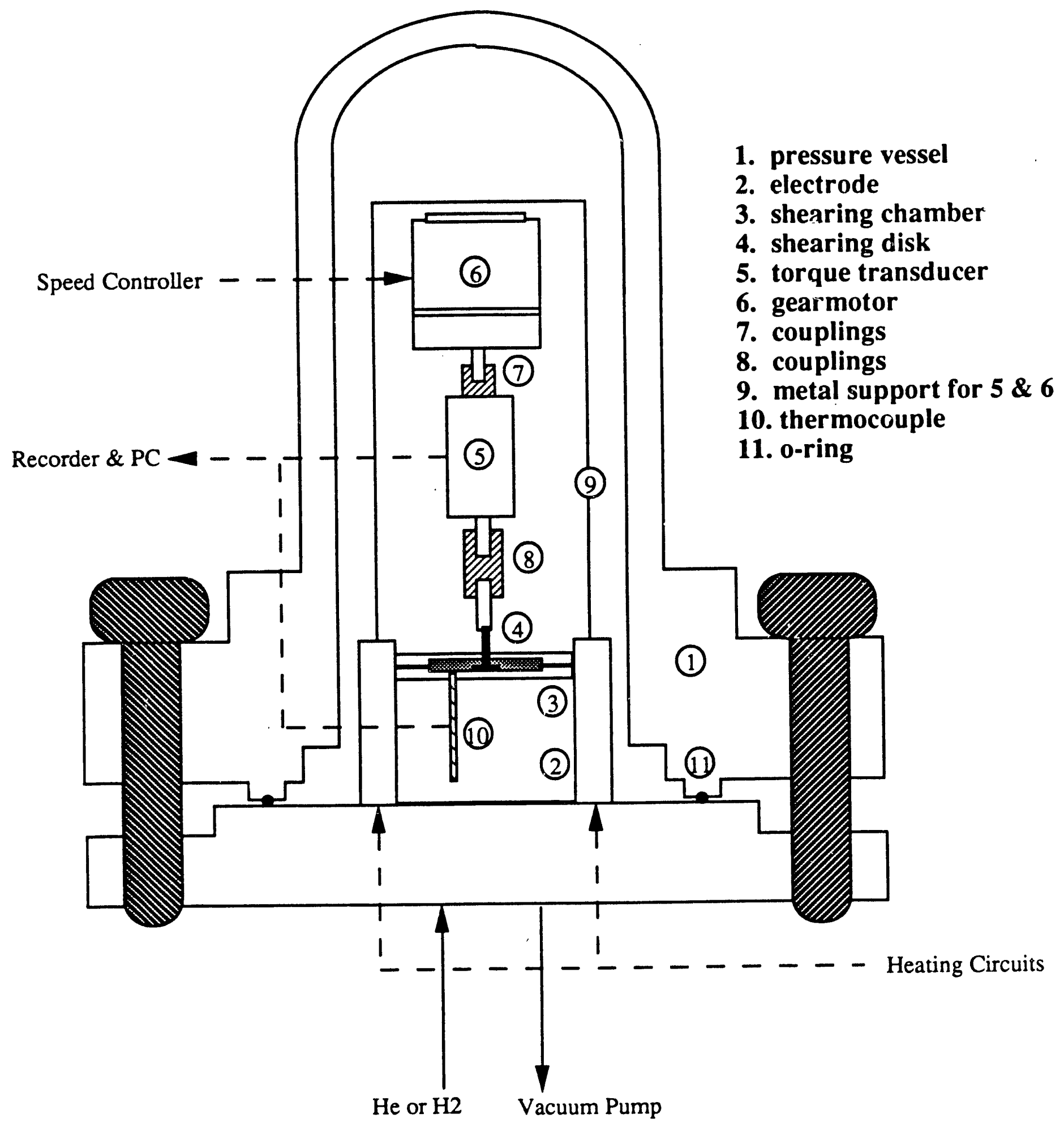

Figure 3: Schematic of the Plastometer 


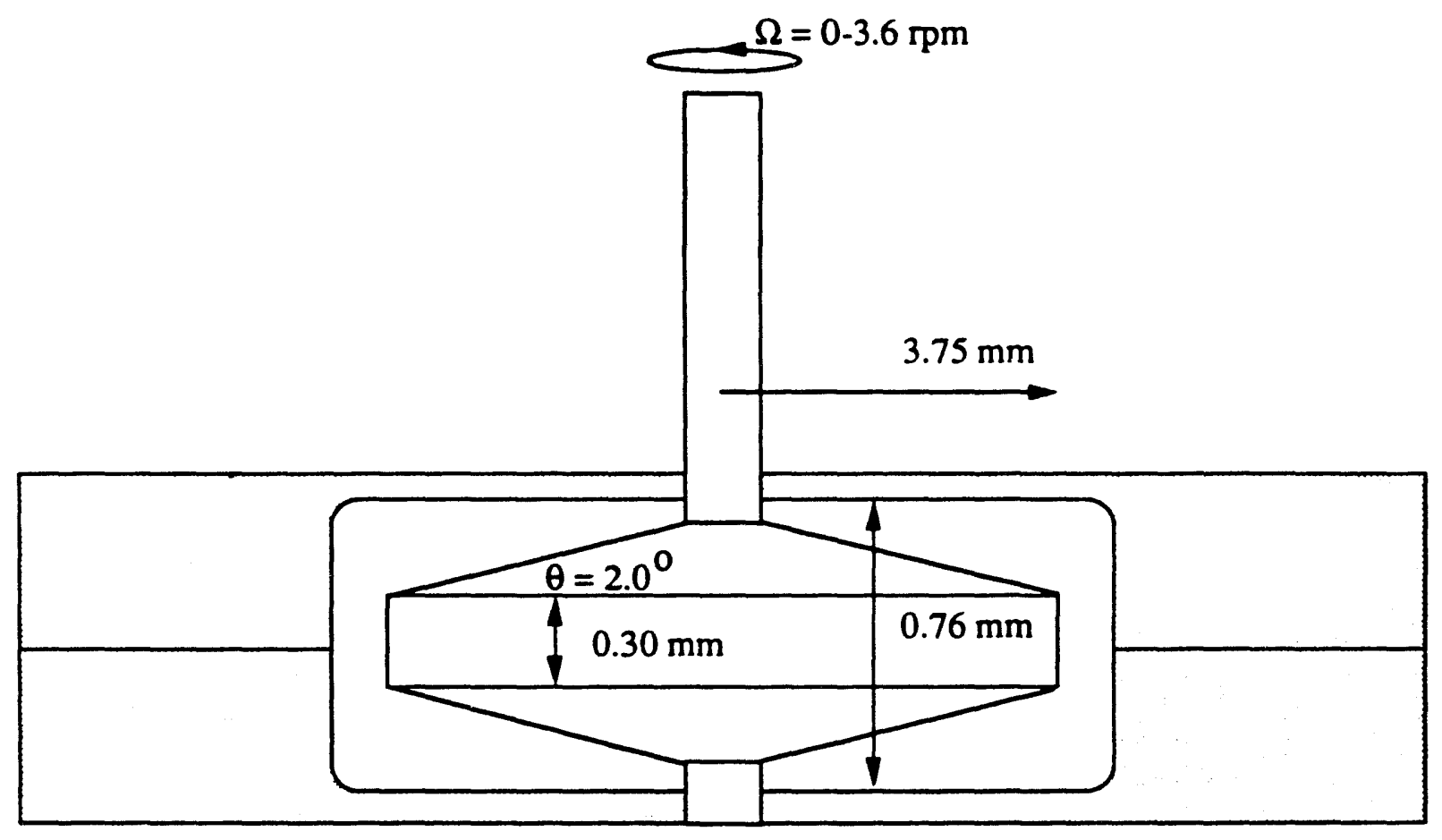

i

Figure 4: Gerjarusak's cone-shaped disk plastometer configuration 
disk rotates between two stationary plates (Bird et. al., 1977 and 1988). For a small cone angle:

$$
\eta=\frac{3 T_{\underline{a}} / 4 \pi R^{3}}{\gamma_{R}}
$$

where $\mathrm{T}_{\mathrm{a}}$ is the apparent torque, $\gamma_{\mathrm{R}}=\Omega / \theta$ is the shear rate of the cone-shaped disk of radius $R$ and cone angle $\theta$, and $\Omega$ is the disk angular velocity. The shearing disk and chamber were machined from nickel superalloy for high temperature strength and resistance to corrosion. The plastometer is enclosed in a high-pressure vessel (316 stainless steel rated for $200 \mathrm{~atm}$ ) that can be evacuated to $0.0001 \mathrm{~atm}$ or charged with hydrogen or helium.

The temperature is measured using a $0.012-\mathrm{mm}$ thin-foil thermocouple attached to the outside surface of the shearing chamber. The response time of the thermocouple is between $2-5 \mathrm{~ms}$ for a stepwise temperature change. With the coal's and metal's thermal diffusivities of $1.5 \cdot 10^{-7} \mathrm{~m}^{2} / \mathrm{s}$ and $5 \cdot 10^{-6} \mathrm{~m}^{2} / \mathrm{s}$ respectively, the temperature gradient across the coal sample and shearing chamber is approximately $50 \mathrm{~K}$ at a $1000 \mathrm{~K} / \mathrm{s}$ heating rate (Carslaw and Jaeger, 1959). This is a conservative estimate since the thermal diffusivity of coal increases with increasing temperature (Badzioch et. al., 1964).

The heating and holding circuits employ a total of six $12-\mathrm{V}$ lead acid automobile batteries. The heating circuit uses two sets of batteries connected in parallel. Each set consists of two batteries connected in 
series for a $24-\mathrm{V}$ output. The temperature holding circuit uses only one set of batteries since the total amperage required to maintain a certain temperature is much less than that required for heating. The magnitude of the electrical current is controlled by two carbon rheostats. The durations of heating and temperature holding are controlled by two solid-state digital relays adjustable from 0.00 to $99.9 \mathrm{~s}$ in $0.01-\mathrm{s}$ increments.

During a typical run, the shearing chamber containing the shearing disk and coal is placed between the electrodes. The shaft of the shearing disk is attached to the couping connected to the transducer. The thermocouple is attached to the surface of the shearing chamber. The pressure vessel's cover is lowered, and the vessel is evacuated to a pressure of $0.0005 \mathrm{~atm}$. Helium is added until the pressure is approximately $1 \mathrm{~atm}$, and the vessel is then evacuated again. The procedure of helium flushing and evacuation is repeated one more time, and the test gas is admitted until the desired pressure is reached. The motor and heating circuits are then activated. The torque and time histories are recorded, using a digital recorder capable of an acquisition rate of 2000 points/s. The data are later transferred to a personal computer.

The plastometer's new configuration has recently been calibrated. The cone-shaped shearing configuration was run at three different shear rates $\left(2.01 \mathrm{~s}^{-1}, 5.16 \mathrm{~s}^{-1}\right.$, and $\left.8.00 \mathrm{~s}^{-1}\right)$ without any material in the shearing chamber. The torque readings were recorded and are 
plotted in Figure 5a. The torque due to friction and misalignment was "steady", i.e. exhibited only small variations with time, and had an average value of $3.18 \cdot 10^{-3} \mathrm{~N} \cdot \mathrm{m}$. The torque did not increase with shear rate, and the average value due to friction and misalignment was subtracted from the torque readings obtained with the shearing chamber filled with the calibration fluid or coal to provide the accurate torque required to shear the material of interest.

To calibrate the new cone-shaped disk configuration, a viscosity standard obtained from a commercial vendor (Cannon, $\eta=5.22 \cdot 10^{6}$ cp) was placed inside the shearing chamber. Three runs were at different shear rates $\left(2.01 \mathrm{~s}^{-1}, 5.16 \mathrm{~s}^{-1}\right.$, and $\left.8.00 \mathrm{~s}^{-1}\right)$. The average frictional torque value was subtracted from the torque data obtained, and using equation 2, the apparent viscosity of the standard was obtained and plotted in Figure 5b. Again, the viscosity values from the plastometer did not vary with the shear rates, and the average viscosity value calculated was $5.58 \cdot 10^{6} \mathrm{cp}$. The calculated value was only $7 \%$ higher than the actual value of $5.22 \cdot 10^{6} \mathrm{cp}$ provided by the manufacturer. This good agreement strongly suggests the reliability of using the new cone-shaped shearing disk configuration and the above data analysis methods to determine the apparent viscosity of molten coal and other thermal softening polymers.

The rapid pyrolysis of coal will be carried out using the screen heater (Figure 6.) similar to that of Anthony et. al. (1974). The coal sample is placed in a folding sheet of stainless steel screen (400 mesh). The 

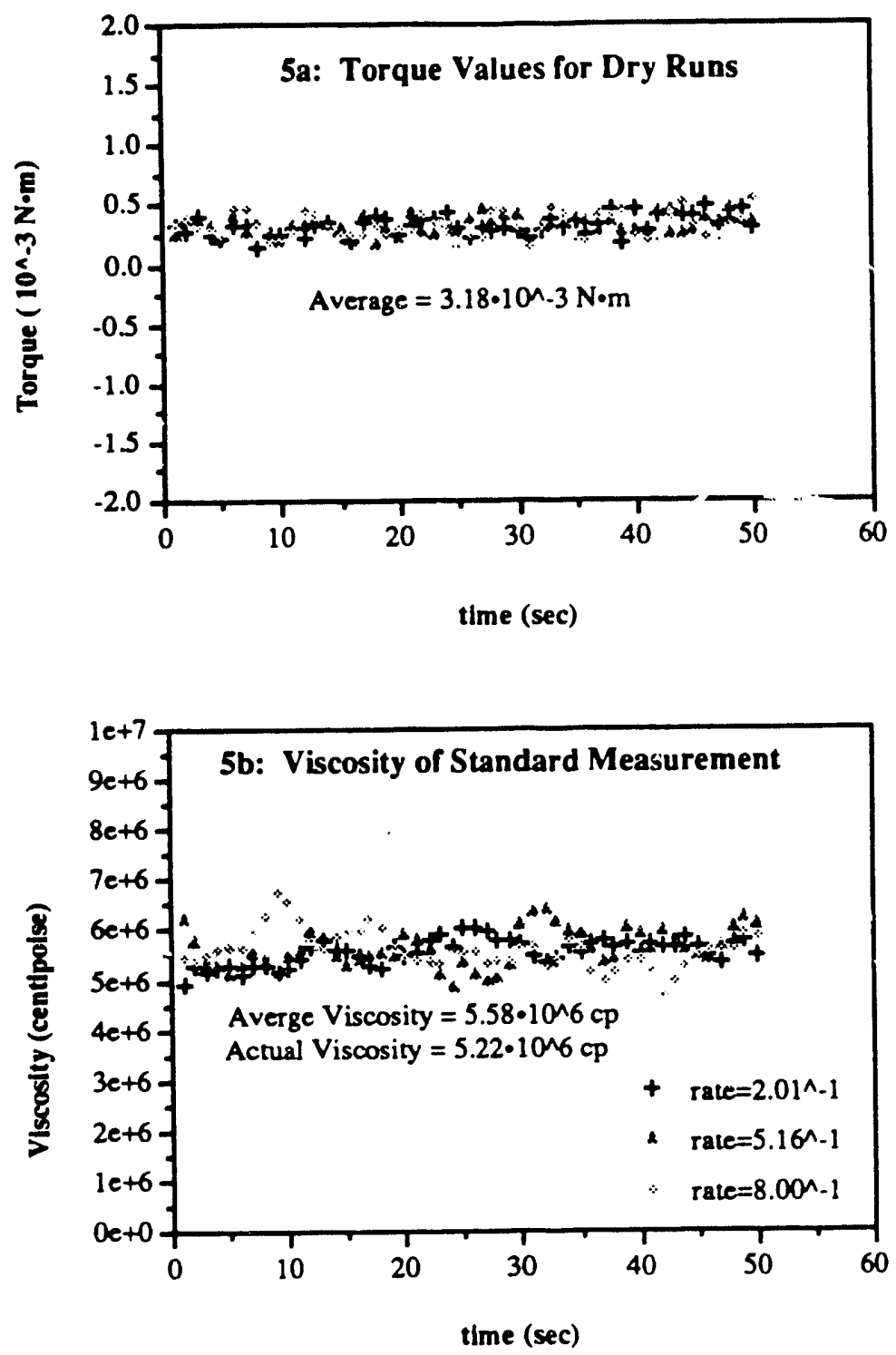

Figure 5: The friction of the plastometer at different shear rates (6a). The viscosity of the standard determined using different shear rates $(6 \mathrm{~b})$ 


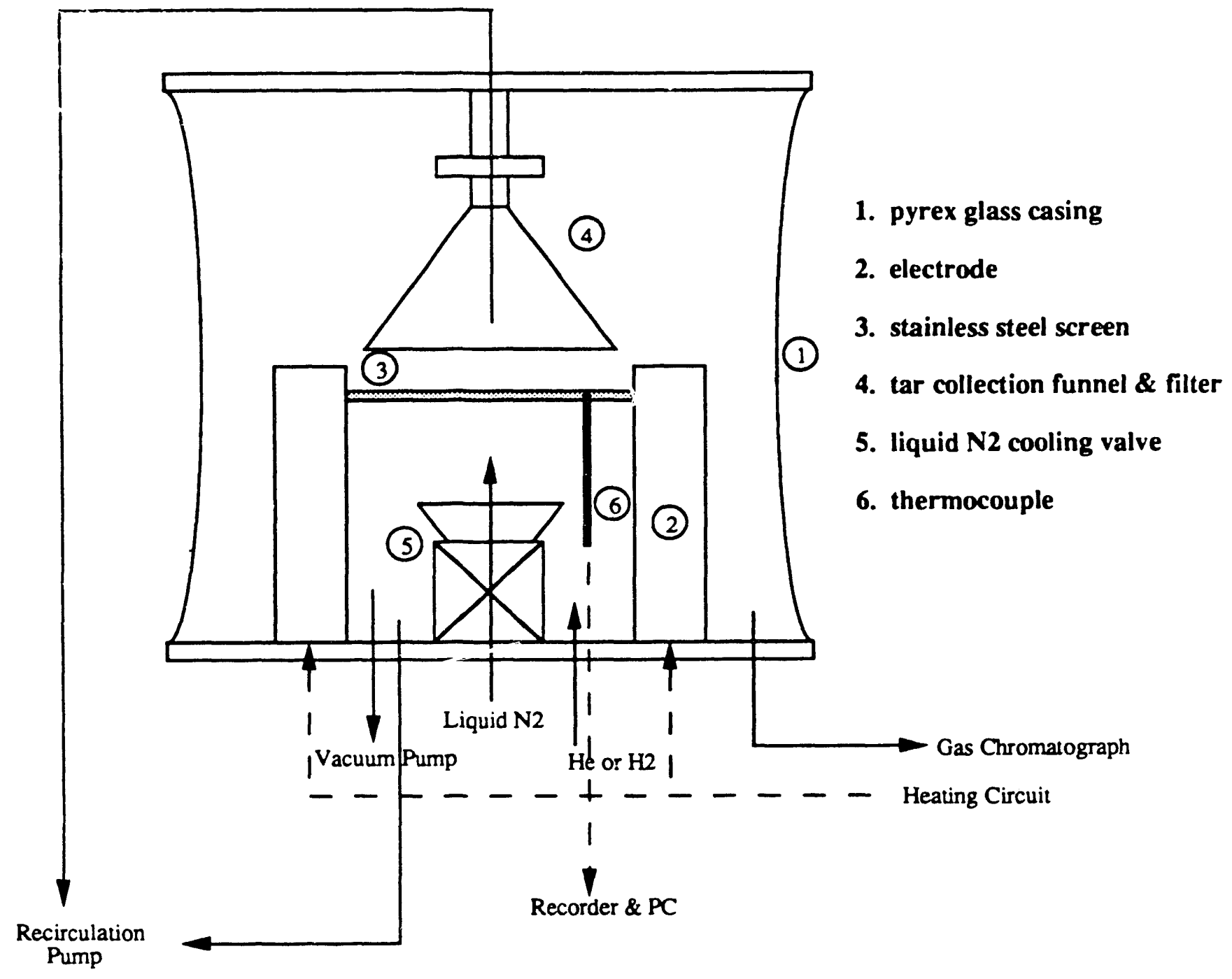

Figure 6: The Screen Heater 
heating and holding circuits are similar to those of the plastometer. The temperature is measured and recorded using a thin-foil thermocouple and a digital recorder. The weight of the screen and coal is measured before and after the pyrolysis. The yield of pyridine extractables is obtained by Soxhlet extraction of the char and screen using pyridine at its boiling point ( $389 \mathrm{~K})$. After the extracted screen and char are vacuum dried at $393 \mathrm{~K}$ for 4 hours, they are reweighed to determine the amount extracted. The molecular weight distribution (MWD) of pyridine extractables can be determined using gel permeation chromatography (GPC) (Fong et. al., 1985b, 1985c). The yield of tar can be determined by weighting the tar trap's filter and foil lining before and after the run. The tar's MWD can also be determined using GPC (Darivakis, 1989). The gaseous products can be analyzed by purging the reactor's gas to the gas chromatograph's gas sampling valve.

The work will concentrate on bituminous coals. The current candidate coal types available are Illinois No. 6, Pittsburgh No. 8, Blue, and Lower Kittanning. Operating conditions will be in the ranges specified above. The work will emphasize the effects of coal type, shear rate, and temperature-time history on the thermoplastic behavior of coal. 
where $a$ is the weight ratio of ultimate coke and volatile yields and fa is the weight fraction of the inert material in the raw coal. The rate of physical melting, $r_{m}$, is given to a very good approximation by:

$$
r_{m}=\left\{M_{o} m_{h} /\left(2 \pi \sigma_{m}^{2}\right)^{1 / 2}\right\} \cdot \exp \left\{\left(T_{m}-T\right)^{2} / 2 \sigma_{m}^{2}\right\}
$$

$M_{O}$ is the amount of pyridine extractables in the parent coal, $m_{h}$ is the heating rate, and $T_{m}$ the mean melting temperature of coal. The quantity $r_{m}$ is thus described as the product of $M_{0}, m_{h}$, and the melting point distribution. Since coal melts over a narrow range of temperature, the melting point distribution is estimated to be normal, with a mean $T_{m}$ and the variance $\sigma_{m}{ }^{2}$ (Fong et. al., 1985c).

Fong (1986) used two different methods to model the transient plastic behavior. First, he fitted the viscosity data directly to the concentrated suspension model. Physical melting was not considered in this model. During resolidification of molten coal, the metaplast formation rate is assumed to be small and:

$$
\mathrm{dM} / \mathrm{dt}=-\mathrm{k}_{2} \mathrm{M}
$$

In addition, $M$ is assumed to be small, and the concentrated suspension model is approximated by:

$$
\mu / \mu^{*}=(27 / 8) \mathrm{M}
$$




\subsection{Theoretical Approach}

In analyzing the plasticity kinetics of coal, a concentrated suspension model (Frankel and Acrivos,1967) relates the viscosity of molten coal to the mataplast concentration:

$$
\mu / \mu^{*}=(9 / 8) /\left[(1-\mathrm{M})^{-1 / 3}-1\right]
$$

where $\mu^{*}$ is the viscosity of the solids-free liquid and $M$ is the intraparticle inventory of softened material (metaplast). From this equation, one can calculate the transient metaplast inventory, $M(T, t)$, from the plasticity data, $\mu(T, t)$, or vice versa.

Fong (1986) and Fong et. al. (1985a, 1985c) used the following sequence of kinetic steps to determine the intraparticle metaplast inventory, $M(T, t)$ :

$$
\begin{aligned}
& \text { Coal (C) ----> Metaplast (M)----> Volatiles (V) + Coke (E) 4) } \\
& \mathbf{k}_{1} \text {, melting } \\
& \mathrm{k}_{2} \\
& \mathrm{dC} / \mathrm{dt}=-\mathrm{k}_{1}\left(\mathrm{C}-\mathrm{f}_{\mathrm{a}}\right)-\mathrm{r}_{\mathrm{m}} \\
& \mathrm{dM} / \mathrm{dt}=\mathrm{k}_{1}\left(\mathrm{C}-\mathrm{f}_{\mathrm{a}}\right)+\mathrm{r}_{\mathrm{m}}-\mathrm{k}_{2} \mathrm{M} \\
& \mathrm{dV} / \mathrm{dt}=\mathrm{k}_{2} \mathrm{M}[1 /(1+\mathrm{a})] \\
& \mathrm{dE} / \mathrm{dt}=\mathrm{k}_{2} \mathrm{M}[\mathrm{a} /(1+\mathrm{a})]
\end{aligned}
$$


The metaplast kinetics (first-order, single-reaction, Arrhenius-type) is thus related to viscosity by:

$$
\mathrm{d}(\mu * / \mu) / \mathrm{dt}=\mathrm{k}_{2}=\mathrm{k}_{02} \exp \left\{-\mathrm{E}_{\mathrm{A} 2} / \mathrm{RT}\right\}
$$

With $k_{2}$ determined, $k_{1}$ is determined by fitting the plasticity data to the first-order, single-reaction, Arrhenius model to determine $\mathrm{k}_{0} 1$ and $\mathrm{E}_{\mathrm{A} 1}$. Using this method, Fong (1986) and Fong et. al. (1985a) were able to fit the transient plasticity data at a heating rate of 450 $\mathrm{K} / \mathrm{s}$ very well (Figure 7.). However, the model did not perform well at other heating rates, implying that the model's parameters $\left(\mathrm{k}_{01}\right.$, $E_{A 1}, k_{02}$, and $E_{A 2}$ ) obtained from the data at one heating rate are not applicable at the other heating rates. Another possibility is that the model itself is not valid for use at different heating rates. Their analysis neglected physical melting.

In a second modeling method, Fong (1986) and Fong et. al. (1985c) obtained the model's parameters $\left(\mathrm{k}_{01}, \mathrm{E}_{\mathrm{A} 1}, \mathrm{k}_{02}\right.$, and $\left.\mathrm{E}_{\mathrm{A} 2}\right)$ directly from screen heater data on the transient inventory of metaplast. Using the screen heater, the inventory of pyridine extractables was quantified at the different stages of pyrolysis and taken as the corresponding intra-coal concentration of metaplast. The model again assume that all the rate constants are described by first-order, single-reaction, Arrhenius equations. In this case, the effect of heating rate was incorporated into the model by the rate of physical melting $\mathrm{r}_{\mathrm{m}}$. By incorporating $\mathrm{rm}$ (equation 9.), Fong (1986) was able 


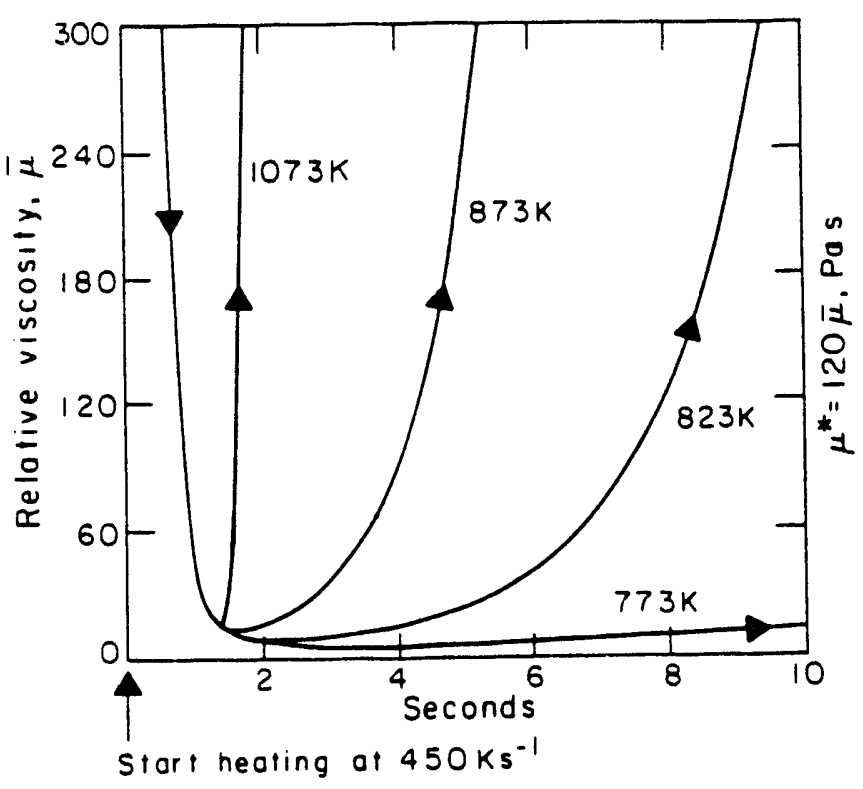

FIGURE 7: PREDICTIONS OF THE RELATIVE VISCOSITY OF SOFTENED COAL BASED ON THE METAPLAST MODEL AND CUNCENTRATED SUSPENSION MODEL. (FONG ET. AL., 1985). 
to make good quantitative predictions of coal plasticity at different heating rates. The comparison of rate parameters $\left(k_{01}, E_{A 1}, k_{02}\right.$, and $\mathrm{E}_{\mathrm{A} 2}$ ) from the two approaches are given in Table 1 below.

\section{Table 1: Rate Parameters for Fong's Models (Fong 1986)}

\section{I. from Apparent Viscosity}

$\mathrm{k}_{01}\left(\mathrm{~s}^{-1}\right)$

245

40.7

$\mathrm{E}_{\mathrm{A} 1}(\mathrm{~kJ} / \mathrm{mole})$

$\mathrm{k}_{02}\left(\mathrm{~s}^{-1}\right)$

$2.0 \cdot 10^{8}$

$\mathrm{E}_{\mathrm{A} 2}(\mathrm{~kJ} / \mathrm{mole})$

133
II. from Metaplast Kinetics

$6.67 \cdot 10^{7}$

28.7

$1.9 \cdot 10^{10}$

42.2

\section{Kinetics Modeling}

Fong (1986) was successful in fitting the plasticity and metaplast inventory data to the kinetics model in which the rate constants were assumed to be first-order, single-reaction, Arrhenius-type equation. However, the thermoplastic behavior of coal is likely to be governed by a large number independent parallel reactions.

Fong (1986) discussed the fact that from his first modeling method, he was unable to obtain from the transient viscosity data of the molten coal the rate parameters $\left(\mathrm{k}_{01}, \mathrm{E}_{\mathrm{A} 1}, \mathrm{k}_{02}\right.$, and $\left.\mathrm{E}_{\mathrm{A} 2}\right)$ which described the transient plasticity behavior of molten coal at different heating rates. He attributed this difficulty to the fact that his first method did not include the rate of physical melting $\left(r_{m}\right)$. 
In his second method, Fong (1986) included physical melting in his model. The rate parameters $\left(\mathrm{k}_{01}, \mathrm{E}_{\mathrm{A} 1}, \mathrm{k}_{02}\right.$, and $\left.\mathrm{E}_{\mathrm{A} 2}\right)$ were obtained by fitting the data on inventory of pyridine extractables from the screen heater experiments to the kinetics model in which the rate constants were assumed to be first-order, single-reaction, Arrheniustype equation. The kinetics of pyridine extractables formation and depletion during a rapid pyrolysis was used to approximate the metaplast formation and depletion kinetics. The rate expression for the generation and destruction of metaplast, $M(T, t)$, was then substituted into the expression for viscosity (concentrated suspension model). Using this method, Fong was able to well describe the thermoplastic behavior of softening coal.

Incorporating physical melting improves the previously mentioned model. However, other than physical melting, Fong's models neither addressed or explicitly treated the effects of heating rate on the metaplast kinetics. In addition, it is desirable to be able to use one set of data at one heating rate to make predictions at other heating rate. Fong (1986) was careful to obtain the kinetics parameters $\left(k_{i}\right.$ 's and $E_{i}$ 's) from the isothermal region of the experiment, which is generally where most of the resolidification of molten coal and the depletion of metaplast occur. In the proposed work, nonisothermal experimental data will be used to obtain kinetics parameters applicable for a broader range of temperature-time histories, including different heating rates. 


\section{Multiple Independent Parallel Reaction Kinetics}

With the need for a model which describes the plasticity and metaplast kinetics more realistically, the multipie independent parallel reaction (MIPR) kinetics model will be used in the proposed studies. MIPR has been used widely by previous students in combustion at MIT to describe kinetics of weight loss and of tar and gas production during coal pyrolysis (Anthony, 1975, Ko, 1988, and Griffin, 1989). The model is described in detail elsewhere (Anthony, 1975 and Howard, 1981). For the proposed studies, all the reactions involved in the plasticity kinetics and metaplast generation and destruction will be modeled using MIPR. For a irreversible, firstorder reaction:

$$
\text { A }--->P
$$

the rate equation and its solution are:

$$
\begin{aligned}
& d A / d t=-k_{A} A \\
& A=\exp \left(-\int_{0}^{t} k_{A} d t\right)
\end{aligned}
$$

where $\mathrm{A}$ is the amount of $\mathrm{A}$ at time $\mathrm{t}$ and $\mathrm{k}_{\mathrm{A}}$ is the rate constant. Using MIPR:

$$
A=A_{1}+A_{2}+A_{3}+\ldots . . A_{n}=\sum_{0}^{n} A_{i}
$$




$$
\begin{aligned}
& \mathrm{dA} \mathrm{A}_{\mathrm{i}} / \mathrm{dt}=-\mathrm{k}_{\mathrm{Ai}} \mathrm{A} \quad, \mathrm{i}=1,2,3, \ldots \mathrm{n} \\
& \mathrm{A}_{\mathrm{i}}=\exp \left(-\int_{0}^{t} \mathrm{k}_{\mathrm{Ai}} \mathrm{dt}\right) \\
& \mathrm{k}_{\mathrm{Ai}}=\mathrm{k}_{0 \mathrm{Ai}} \exp \left(-\mathrm{E}_{\mathrm{i}} / \mathrm{RT}\right)
\end{aligned}
$$

where $i$ denotes a particular reaction $i, k_{0 A i}$ and $E_{i}$ are respectively the preexponential factor and activation energy for reaction i. Assuming that all the reactions have the same preexponential factor $\left(\mathrm{k}_{0 \mathrm{Ai}}=\mathrm{k}_{0 \mathrm{~A}}\right)$ and that the number of reactions are large enough to permit the activation energies to be expressed as a normal distribution, $F(E)$ :

$$
A=\int_{0}^{\infty} \exp \left\{-k_{0 A} \cdot \int_{0}^{t} \exp (-E / R T) d t\right\} \cdot F(E) d E
$$

Following Anthony et. al. (1975) one would choose $F(E)$ to be a Gaussian such that:

$$
F(E)=\left(2 \pi \sigma_{E}^{2}\right)^{-1 / 2} \cdot \exp \left\{\left(E_{0}-E\right)^{2} / 2 \sigma_{E}^{2}\right\}
$$

where $E_{0}$ and $\sigma_{E^{2}}$ are respectively the mean activation energy and its variance.

When the temperature-time history is linear (constant heating rate), the rate constant expression at any time $t$ is: 
$\frac{k}{k_{0 A}}=\frac{\int_{0}^{\infty} \exp \left\{\left(-k_{0 A}\right) \cdot \int_{0}^{t} \exp (-E / R T) d t-\left(E_{0}-E\right)^{2} / 2 \sigma_{E}^{2}-E / R T\right\} d E}{\int_{0}^{\infty} \exp \left\{\left(-k_{0 A}\right) \cdot \int_{0}^{t} \exp (-E / R T) d t-\left(E_{0}-E\right)^{2} / 2 \sigma_{E}^{2}\right\} d E}$

or at any temperature $\mathrm{T}$ (Howard et al., 1986):

$\frac{k}{k_{0 A}}=\frac{\int_{0}^{\infty} \exp \left\{\left(-k_{0 A} / m\right) \cdot \int_{0}^{T} \exp (-E / R T) d T-\left(E_{0}-E\right)^{2} / 2 \sigma_{E}{ }^{2}-E / R T\right\} d E}{\int_{0}^{\infty} \exp \left\{\left(-k_{0 A} / m\right) \cdot \int_{0}^{T} \exp (-E / R T) d T-\left(E_{0}-E\right)^{2} / 2 \sigma_{E}^{2}\right\} d E}$

When the temperature is constant:

$$
\frac{k}{k_{0 A}}=\frac{\int_{0}^{\infty} \exp \left\{-k_{0 A} t \cdot \exp (-E / R T)-\left(E_{0}-E\right)^{2} / 2 \sigma_{E}^{2}-E / R T\right\} d E}{\int_{0}^{\infty} \exp \left\{-k_{0 A} t \cdot \exp (-E / R T)-\left(E_{0}-E\right)^{2} / 2 \sigma_{E}^{2}\right\}}
$$

Only four parameters $\left(A(t=0), E_{0}, \sigma_{E}{ }^{2}, k_{0 A}\right)$ are required to correlate the MIPR model to kinetics data for a reaction contributing to plasticity and/or metaplast generation and depletion data. For 
example, equation 22 can be used to find the rate constant or metaplast concentration during resolidification with the following rate equation:

$$
\mathrm{dM} / \mathrm{dt}=-\mathrm{k}_{2} \mathrm{M}
$$

Equations $21 \mathrm{a}$ and $21 \mathrm{~b}$ could be used for the initial softening of coal since the process occurs during the linear heat up period of the experiment.

In addition, the values $E_{0}$ ano $\sigma_{E^{2}}^{2}$ also shed light on interesting features of the reaction set of interest including its "chemical diversity" as expressed by the range of activation energies for which reactions make significant contributions to the rate process of interest. The variance of $F(E)$ determines the spread around the mean activation energy. A big spread implies that the overall reaction consists of a large number of independent reactions in parallel. A small spread means that the number of independent reactions is few. Further, one can compare the mean activation energy value of the reaction of interest to activation energy values found in other studies of coal devolatization to gain insights on the possible types of reactions occurring, e.g. cracking. 
Coal-Type and Pressure Effects:

Ko et. al. (1986 and 1988) correlated tar yields with coal type and pressure by assuming that tar is generated during pyrolysis via the global mechanism:

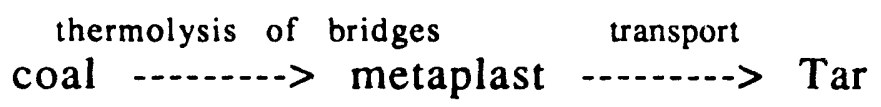

The structural-chemical factors considered in the coal type correlation were: 1) the identities and numbers of bridges between aromatic clusters of the coal and 2) the concentration of hydrogen available to stabilize free radicals created by bridge scission reactions (Ko et. al., 1986).

Ko et. al. defined a coal-type parameter for correlating tar yields as:

$$
\mathrm{X}_{\mathrm{tar}}=\frac{\# \text { of labile bridges }}{\# \text { of cross-linked bridges }} \text { \# of abstractable } \mathrm{H}
$$

The formulation and computation of each of these three factors are described by Ko (1988). Each factor can be calculated solely from a $\mathrm{C}, \mathrm{H}, \mathrm{O}$, and $\mathrm{S}$ elemental analysis of the raw coal. Maximum tar yield at a given pressure is linearly correlated with the coal-type parameter by:

Tar Yield $(w t \%$ dmmf $)=\alpha(P)+\beta(P) X_{\text {tar }}$ 
The coefficients $\alpha$ and $\beta$ are pressure dependent and are determined by best fitting them to experimental tar yield data. Typical results are shown in Figure 8 from Ko et. al. (1988).

Equation 24 shows that the amount of metaplast generated during coal pyrolysis can be determined from the tar yield if the transport term is unimportant as was taken to be the case in many of Ko's studies or if one has knowledge of the pertinent transport rates. The present plan is to use $X_{t a r}$ and an equation like 26 to estimate maximum metaplast yields for different coal types, and thereby to estimate the maximum fluidity for different coals.

\section{Safety}

Hazardous chemicals used in this research include methylene chloride and acetone as cleaning solvents and pyridine for solvent extraction and GPC analysis. All work involving cleaning with methylene chloride and acetone and extraction of coal char using pyridine will be done under a fume hood. When the work involves the use of hazardous chemicals, safety glasses and rubber gloves will be worn. The electrical connections of the heating circuits are well insulated to minimize the possibility of electrical shock. 


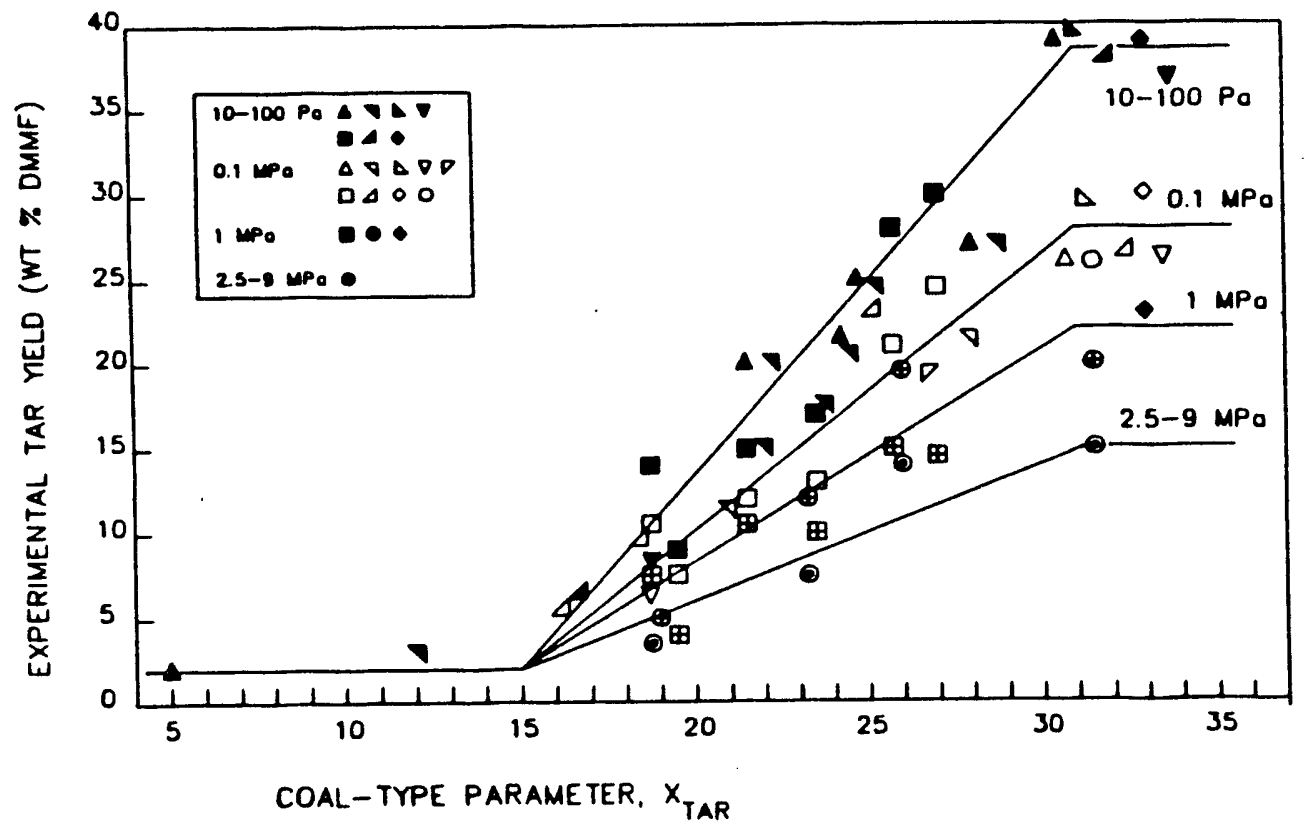

FIGURE 8: CORRELATION OF TAR YIELDS AT DIFFERENT PRESSURE (KO ET. AL., 1988) 
5. Timetable

9/89 Arrived at MIT

1/90 Doctoral Qualifying Examination completed

2/90 Practice School started

5/90 Practice School completed

$6 / 90$ Began Research on Coal Plasticity

8/90 Plastomieter refurbished

$12 / 90 \quad$ Literature review completed

2/91 Plastometer modification completed

4/91 Plastometer calibrated

$5 / 91 \quad$ Began systematic experimental studies on coal plasticity

$6 / 91$ Complete doctoral thesis proposal

$12 / 91$ Begin work on metaplast and tar yields

1/91 Begin modeling and correlation work

$6 / 92$ Initial experimental work completed

9/92 Complete experimental work

$12 / 92$ Complete modeling and correlation work

$1 / 93$ Begin writing Ph.D. thesis and collect additional experimentaldata if necessary

5/93 Complete writing of and defend Ph.D. thesis 


\section{References}

Anthony, D. B., J. B. Howard, H. P. Meissner, and H.C. Hottel, "Apparatus for High-Temperature High-Pressure Coal Hydrogenation Kinetics," Review of Scientific Instruments, 45 , 1974.

ASTM "Standards on Coal and Coke" 1974 Annual Book of ASTM Standards. Philadelphia, PA, 1974.

Bird, R.B., R. C. Armstrong, and O. Hassager, Dynamics of Polymeric Liquids, Vol. 1, Wiley, New York, 1977 and 1988.

Carslaw H. S. and J. C. Jaeger, Conduction of Heat in Solids, Second ed., Oxford University, Oxford, 1959

Darivakis, G. S., "Primary Liquid Products from Rapid Pyrolysis of Coals and Lignites," Sc.D Thesis, Department of Chemical Engineering, MIT, Cambridge, MA, 1989.

Davies, C. E., S. T. Pemberton, and J. Abrahamson, "Capillary Viscometry of a New Zealand Coal at High Pressures and Shear Stresses" Fuel, 62, 1983.

Badzioch, S., D. R. Gregory, and M. A. Field, Fuel, 43, 1964.

Fitzgerald, D., "The Kinetics of Coal Carbonization in the Plastic State" Fuel, 35, 1956.

Fong, W. S., W. A. Peters, and J. B. Howard, "Apparatus for Determining High-Temperature High-Pressure Coal Plastic Behavior Under Rapid Heating Conditions," Review of Scientific Instruments, 56, 1985.

Fong, W. S., Y. F. Khalil, W. A. Peters, and J. B. Howard, "Plastic Behavior of Coal Under Rapid-Heating High-Temperature Conditions," Fuel, 65, 1985.

Fong, W. S., W. A. Peters, and J. B. Howard, "Kinetics of Generation and Destruction of Pyridine Extractables in a Rapidly pyrolyzing Bituminous Coal," Fuel, 65, 1985. 
Fong, W. S., "Plasticity and Agglomeration in Coal Pyrolysis, " Sc.D. Thesis, Department of Chemical Engineering, MIT, Cambridge, MA, 1986.

Frankel N. A. and A. Acrivos, "On the Viscosity of a Concentrated Suspension of Solid Spheres" Chemical Engineering Science, 22, 1967.

Griffin, T. P., "Intraparticle Secondary Reactions of Tar during Bituminous Coal Pyrolysis," Ph.D Thesis, Department of Chemical Engineering, MIT, Cambridge, MA, 1989

Howard, J. B., "Fundamentals of Coal Pyrolysis and Hydropyrolysis" in Chemistry of Coal Utilization, Second Suppl. Vol., edited by M.A. Elliott, Wiley, New York, 1981.

Howard, J. B., W. S. Fong, and W. A. Peters, "Kinetics of Devolatization," NATO Advanced Research Workshop on "Fundamentals of the Physical-Chemistry of Pulverized Coal Combustion," Les Arcs, France, 1986.

Khan, M. R. and R. G. Jenkins, "Thermoplastic Properties of Coal at Elevated Pressures," Fuel, $\underline{63}, 1984$.

Ko, G. H., W. A. Peters, and J. B. Howard, "Correlation of Tar Yields from Rapid Pyrolysis with Coal Type and Pressure," Fuel, $\underline{66}$, 1987.

Ko, G. H., D. M. Sanchez, W. A. Peters, and J. B. Howard, "Correlations for Effects of Coal Type and Pressure on Tar Yields from Rapid Devolatization," Twenty-Second Symposium (International) on Combustion, 1988.

Ko, G. H., "Pyrolysis of Different Coal Types," Ph.D Thesis, Department of Chemical Engineering, MIT, Cambridge, MA, 1988.

Loison, R., A. Peytavy, A. F. Boyer, and R. Grillot, "The Plastic Properties of Coal" in Chemistry of Coal Utilization, Suppl. Vol., edited by H. H. Lowry, Wiley, New York, 1963.

Oh, M. S., "Softening Coal Pyrolysis," Sc.D Thesis, Department of Chemical Engineering, MIT, Cambridge, MA, 1985. 
Stephens, J. N., "A New Coal Plastometer" Fuel, 42, 1963.

Whitehurst, D. D., "Coal Liquefaction Fundamentals" ACS Symposium Series, 139, 1980. 

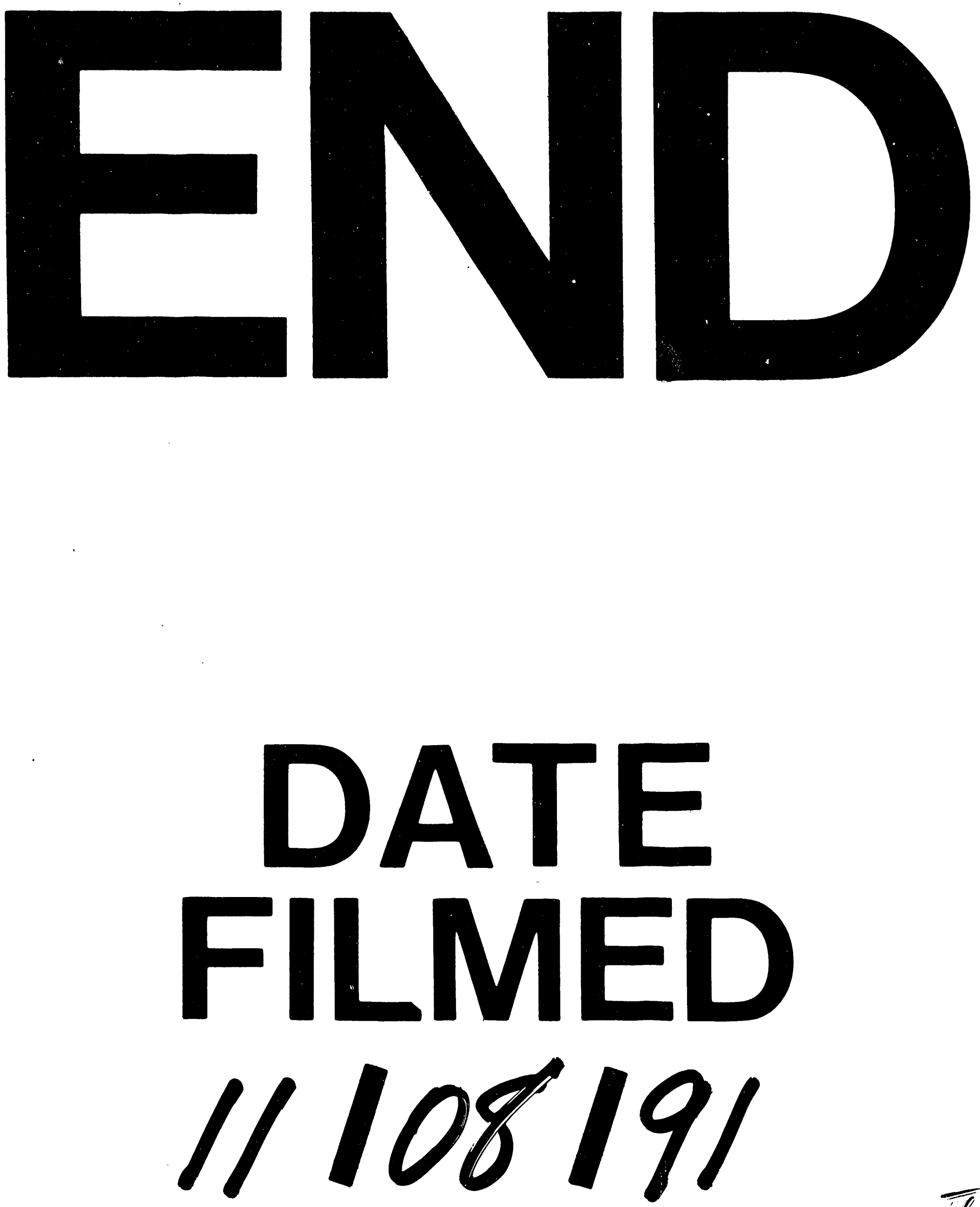

" 
